\begin{tabular}{|c|c|}
\hline \multirow{3}{*}{ 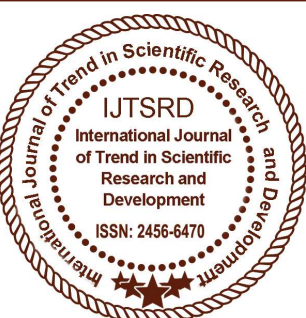 } & $\begin{array}{l}\text { International Journal of Trend in Scientific } \\
\text { Research and Development (IJTSRD) }\end{array}$ \\
\hline & International Open Access Journal \\
\hline & ISSN No: 2456 - 6470 | www.ijtsrd.com | Volume - 2 | Issue -3 \\
\hline
\end{tabular}

\title{
A Review on Biomass Energy Production using Different Technologies and its Utilization in India
}

\author{
Vishal Soni \\ Department of Electrical \\ Engineering, Poornima College of \\ Engineering, Sitapura, Jaipur, \\ Rajasthan, India
}

\author{
Mr. Pravin Kumar \\ Assistant Professor, Department \\ of Electrical Engineering, \\ Poornima College of Engineering, \\ Sitapura, Jaipur, Rajasthan, India
}

\author{
Dr. Deepika Chauhan \\ Associate Professor, Department \\ of Electrical Engineering, \\ Poornima College of Engineering, \\ Sitapura, Jaipur, Rajasthan, India
}

\section{ABSTRACT}

Biomass can be promptly changed over into strong, fluid or vaporous energizes and from that point can be utilized in production of electricity. so due to the increase in population the demand of electricity is increasing day by day. so for full-fill the request of the creation of vitality there are diverse advances are utilizing of biomass and furthermore its usage of vitality in elevated structure. This paper is summarizing about the production of biomass energy using different technologies and its utilization in different sectors.

Keywords: Biomass, energy demand, waste products, technologies, utilization of biomass

\section{INTRODUCTION}

Biomass is sustainable energy source since more trees and harvests are planted and Biomass gets vitality from the sun. With an expected creation of around 350 million tones of Agrarian waste each year, lingering biomass is equipped for alleviation of unsafe outflows to the degree of 300 million tons per annum. Amid photosynthesis process, daylight gives plants the vitality they need to change over water and carbon dioxide into oxygen and glucose (sugars). These sugars supply plants, creatures and people that eat plants with vitality. Biopower is the utilization of biomass to create power. This paper is advancements associated with biopower frameworks are direct combustion, co-firing, gasification, pyrolysis, anaerobic process, fermentation and also tells about the use of waste products in high rise buildings. This calls for assurance furthermore, arranging the losses to evaluate the vitality put away in them. This assesses how biomass vitality adds to the vitality request of the building.

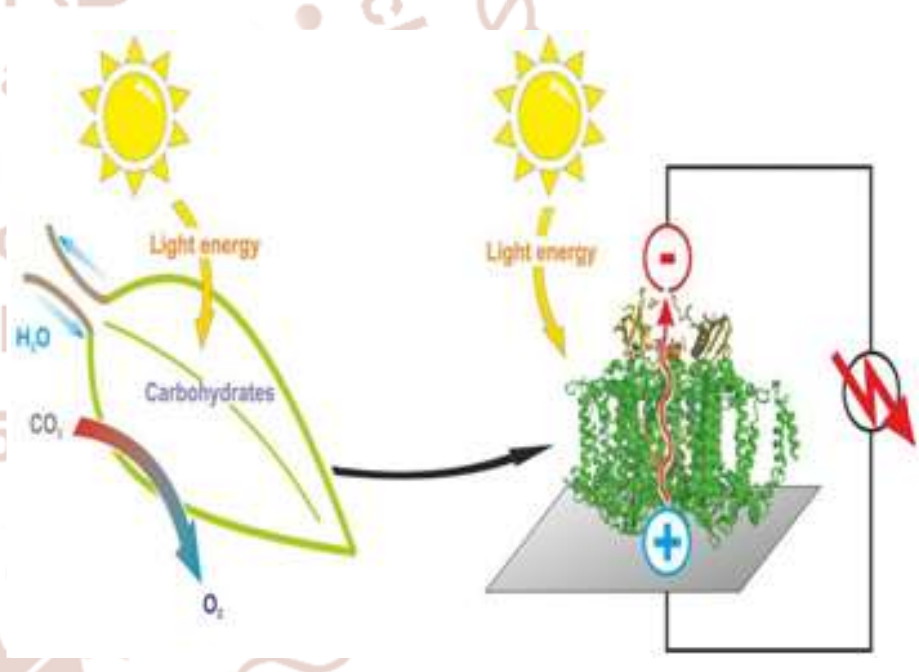

Fig1: Photosynthesis and energy production process

\section{II.TECHNOLOGY}

\section{i) Direct Combustion (Incineration):-}

Combustion is the procedure by which over $90 \%$ of the world's essential vitality supply is acknowledged with a specific end goal to give warmth and vitality administrations, for example, materials handling counting sustenance planning; space warming, ventilation and cooling; power, and transportation. The non-warm wellsprings of vitality in the essential vitality blend are hydro and atomic power, and also sustainable sources. Just around $11 \%$ of the powers 
utilized are biomass assets, and the extensive variety of powers utilized as a part of burning include: coals going from anthracite (a relatively unadulterated type of carbon) to lignite or dark colored coal; peat; gaseous petrol; rough what's more, refined oils including fluid oil gas (LPG), fuel, diesel and lamp oil. Coal, oil, gas and biomass, at shares individually $23.3,35.7,20.3$, and $11.2 \%$, are the current significant essential vitality hotspots for the world. Ignition is a procedure in which the fuel is singed with the oxygen from the air to discharge the put away compound vitality as warmth in burners, boilers, inner ignition motors and turbines. The least complex strategy for extricating vitality from biomass is immediate burning. Ignition is the procedure of consuming the strong, semidried biomass counting wood, horticultural buildups, sugar stick baggase and civil strong waste. The warmth gotten from burning of biomass can be utilized for a few helpful procedures, for example, cooking, mechanical warmth, steam age, age of electrical vitality from steam and so on. Wood, trees, cultivate items are scorched to deliver power and process warm/steam. Such plants are situated close cultivate site or woodlands.

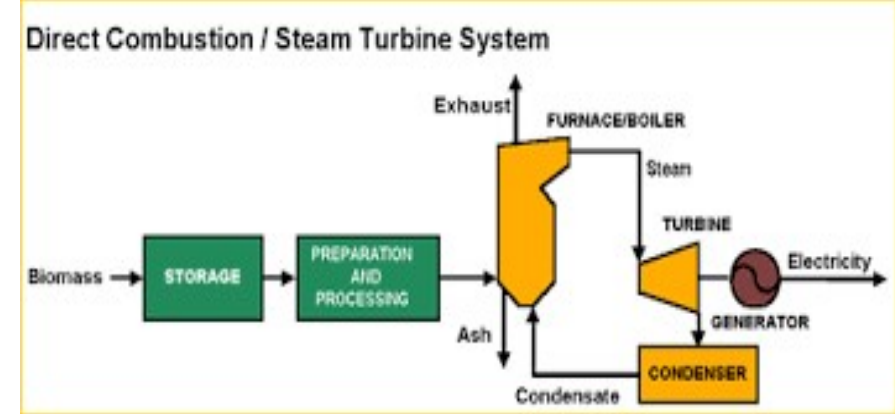

Fig 2:direct combustion process

\section{ii) Gasification:}

The pith of gasification process is the transformation of strong carbon fills into carbon monoxide by thermochemical process. The gasification of strong fuel is refined in air fixed, shut chamber, under slight suction or weight with respect to encompassing weight. Gasification is a procedure that uncovered a strong fuel to high temperatures and restricted oxygen to change over biomass into a vaporous fuel. The gas is a blend of carbon monoxide, carbon dioxide, nitrogen, hydrogen and methane. The fuel gas at that point can be utilized as a part of a cylinder driven motor, high effectiveness gas turbine which runs an electric generator for creating power. Biomass gasification can be utilized for both warm and electrical application. Biomass gasifier changes over the strong biomass which are essentially wood squander, farming buildup, sugar stick bagasse and so on into an ignitable gas blend. In India there is extensive variety of gasifiers accessible with limits differing from $20 \mathrm{KW}$ to $500 \mathrm{KW}$ for electrical applications.

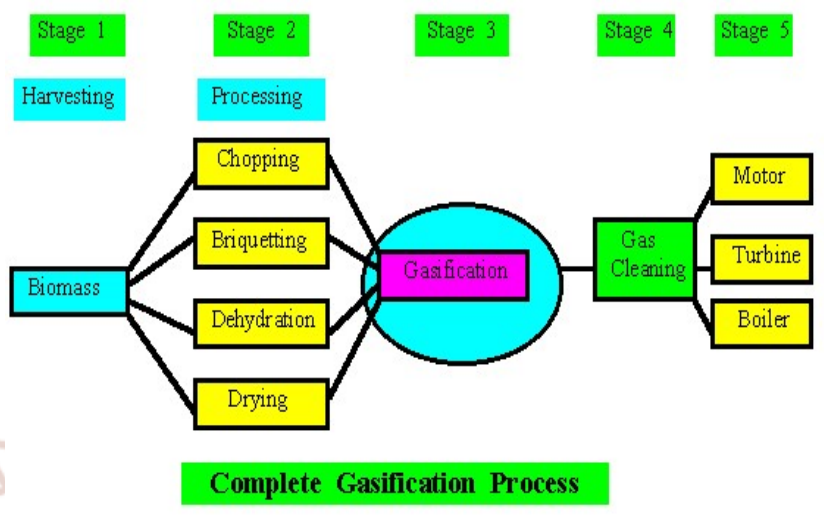

Fig3: Gasification process

Gasification of biomass and utilizing it set up of customary direct consuming gadgets will bring about funds of no less than $50 \%$ in fuel utilization.

\section{iii) Fermentation: -}

Fermentation is a metabolic procedure that expends sugar without oxygen. The items are natural acids, gases, or liquor. It happens in yeast and microorganisms, and furthermore in oxygen-starved muscle cells, as on account of lactic corrosive Fermentation. The Fermentation is a procedure of decay of natural issue by microorganism, for example, microscopic organisms what's more, yeasts. Fermentation breaks down grains, sugar to frame ethanol and carbon dioxide by yeast.

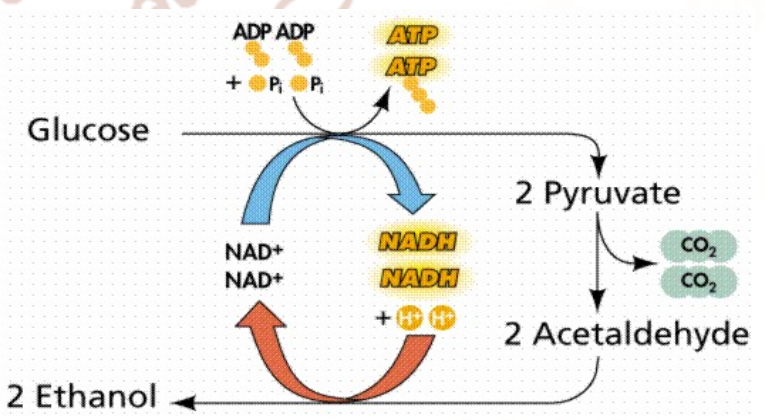

Fig 4: Fermentation

Ethanol can be mixed with gas (petroleum) to create gasohol (90\% petroleum and 10\% ethanol). Ethanol has more prominent potential for use as a mechanical dissolvable and concoction than as a fluid fuel. Ethanol aging of biomass happens at 20 to 30 degrees centigrade. The procedure takes around 50 hours. Yield is around $90 \%$ fluid. This contains around 10 to 
$20 \%$ of liquor relying on the resistance of yeast to liquor. The warming esteems for the alcohols are essentially lower than for the oil powers with that of ethanol being around $66 \%$ that of fuel.

\section{iv) Pyrolysis:}

Pyrolysis is a procedure through which biomass can be changed over into solids, fluids and gases warming in a shut vessel at temperatures of 500-900 degrees centigrade.

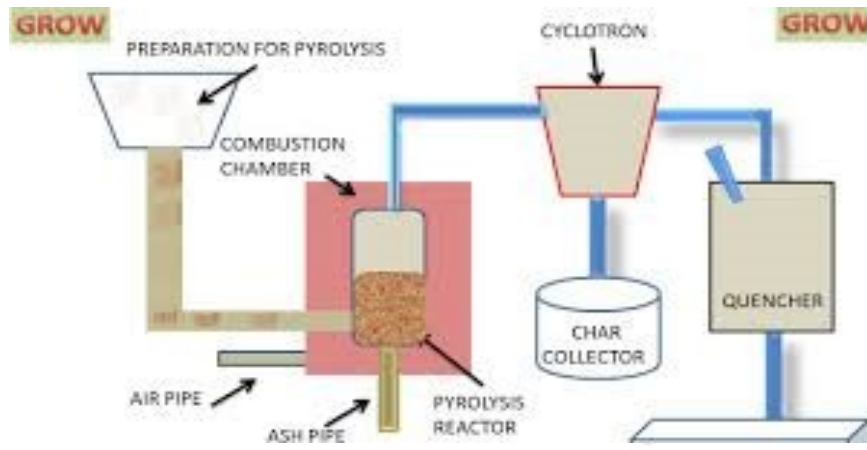

Fig 5: pyrolysis process

Pyrolysis speaks to warming the biomass to drive off unstable issue and taking off behind the charcoal. This procedure has multiplied the vitality thickness of the first material. The unstable material gathered produces a gas which is rich in hydrogen and carbon monoxide. The gases delivered are a blend of nitrogen, methane, carbon monoxide, carbon dioxide and other hydrocarbons. Notwithstanding gas, fluid energizes can be delivered from biomass known as pyrolysis oil, which can Pyrolysis is a thermochemical treatment, which can be connected to any natural (carbon-based) item. In this treatment, material is presented to high temperature, and without oxygen experiences compound and physical division into various particles. This permits to get items with an alternate, regularly more unrivaled character that unique buildup. On account of this element, pyrolysis turns out to be progressively vital process for now industry - as it permits to convey far more prominent incentive to normal materials and waste.

\section{iv) Digestion:}

Anaerobic decomposition is a kind of biochemical transformation including microbial assimilation of biomass. The procedure and final result rely on the microorganisms developed and culture conditions. The feedstock utilized for anaerobic assimilation is urban (civil waste), straw of rice, wheat, sugar stick bagasse and so forth., creature compost and human sewage and so forth. Within the sight of dampness and nonappearance of oxygen, most natural materials will experience characteristic maturation in which 60$80 \%$ of the carbon in the natural material is changed over to a blend of carbon dioxide, methane, hints of hydrogen sulphide and nitrogen. Anaerobic absorption forms have been utilized for a long time for change to gases and fluids. The sewage treatment offices have utilized for the most part for creating fuel gas and now and again to produce electrical power from such biogas. In India anaerobic processing plants are usually known as biogas plants as well as Gober gas plants. In such plants slurry of bovine fertilizer and water is encouraged to the digester and is permitted to age for half a month. The biogas discharged contains around $55 \%$ of methane which is utilized as a fuel.

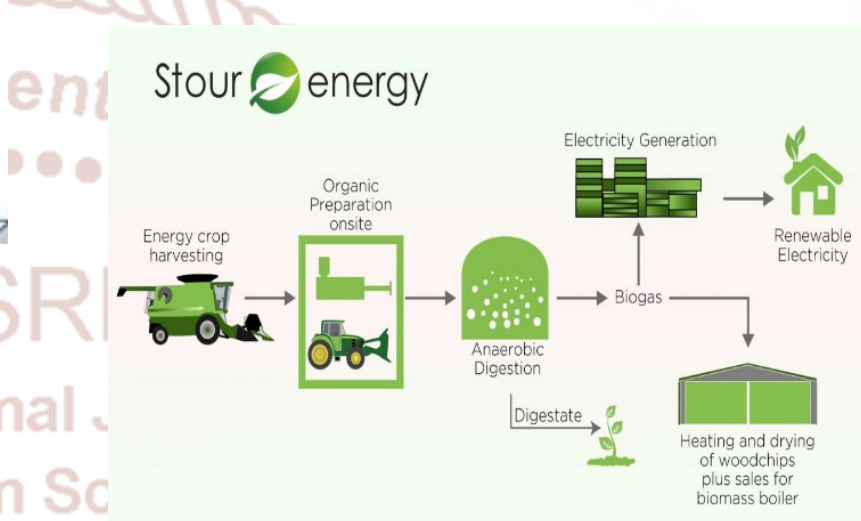

Fig 6:digestion process

\section{Utilization of Biomass: -}

India is the world's second biggest sugarcane maker and a noteworthy producer of molasses derived ethanol. The conditions of Uttar Pradesh, Maharashtra, Karnataka and Tamil Nadu contributed in excess of 80 percent of the nation's aggregate sugarcane creation in 2010-11. Ethanol in India is fundamentally created by the aging of molasses. It is evaluated that $85-100 \mathrm{~kg}$ of sugar $(8.5-10 \%)$ and $35-$ $45 \mathrm{~kg}(3.5-4.5 \%)$ of molasses can be gotten from 1 ton of sugarcane though the recuperation of ethanol from molasses is $22-25 \%$, according to Indian norms. Biomass usage for sustenance, energizes and chemicals. Biomass Biomass alludes to all the issue that can be acquired from photosynthesis. Most vegetable species utilize sun-based vitality to make sugars from carbon dioxide and water. They store this vitality as glucose or starch particles, oleaginous, cellulose, and lignocellulose. Biomass gives off an impression of being an alluring feedstock for three principle reasons. To begin with, it is an inexhaustible asset that could be reasonably created later on. 
Second, it seems to have considerably positive natural properties, prominently the reusing of carbon in the organic procedures, bringing about no net arrivals of carbon dioxide and a low Sulphur content. Third, it seems to have critical financial potential gave that petroleum product costs increment, significantly, in the future. The extraordinary flexibility of biomass as a feedstock is obvious from the scope of materials that can be changed over into different strong, fluid, and vaporous energizes utilizing natural and thermochemical transformation forms. Four general classifications of potential biomass feedstocks can be distinguished: (1) natural urban or mechanical squanders; (2) horticultural harvest deposits and squanders including compost, straw, bagasse, and ranger service squander; (3) existing uncultivated vegetation including stands of trees, bushes, bracken, heather, and so forth; and (4) vitality estates, which include planted vitality trims either ashore brought into generation for that reason, arrive occupied from other farming creation, or as catch crops planted on gainful land. Biomass energizes, including wood, trim waste and dung cake represent $47 \%$ of the aggregate vitality utilization in India and are the real source (85-90\%) of cooking-vitality in provincial India.

\section{III.APPLICATIONS OF BIOMASS}

Biomass densification or briquetting: This is the way toward compacting free biomass feedstocks into a uniform thick shape, delivering a higher quality fuel. Better and more steady warm and physical characteristics take into consideration more entire ignition of briquettes, giving more noteworthy proficiency, diminished emanations, what's more, more noteworthy control for private and modern applications. Briquettes offer less demanding transport, stockpiling, and mechanical dealing with in both family and mechanical settings. Briquettes can be proficiently delivered utilizing generally basic advances. Stalks, husks, bark, straw, shells, pits, seeds, sawdust-for all intents and purposes any strong natural result of rural or silvicultural gathering — can be utilized as a feedstock. Biomass squanders with generally low dampness content (under 15\%) are most reasonable for proficient creation of briquettes.

Ethanol gel: Ethanol gel is a spotless consuming fuel that comprises of gelatinized ethanol bound in a cellulose thickening operator and water. Cookstoves uncommonly outlined for use with ethanol gel have been produced over the most recent couple of years, as have ethanol gel burners that can be retrofitted into a few customary African cooking stoves. Utilized as a part of such apparatuses, ethanol gel is an exceedingly controllable, effectively lit cooking fuel with a warming productivity of around $40 \%$. Beginning business sector infiltration has taken put in a few nations in Africa, for example, Zimbabwe, Malawi, and South Africa. Experience has demonstrated that ethanol gel can substitute for wood energizes and lamp fuel, balance out family unit vitality advertises, and decrease $\mathrm{CO} 2$ outflows and indoor air contamination.

Enhanced cookstoves: The key use for fuelwood, charcoal, and different types of biomass in the UEMOA is for cooking. Using smokeless, proficient, and minimal effort stoves that exist in the commercial centre today can help lessen wood fuel request, enhance indoor air contamination, and reduce deforestation.

\section{IV.FUTURE SCOPE}

The focal point of the advancement is on consistent streamlining. The transformation of crude material into more vitality thick structures encourages transport, stockpiling and use through whatever remains of the esteem chain. One illustration at present being worked on that would rearrange future imports is the warm preparing of biofuels to deliver a more productive sort of pellet with a higher vitality esteem. Worldwide exchange biomass for control age is as yet restricted. Future increments in biomass exchange will probably imply that fuel is delivered a long way from where it is expended. This features the requirement for an institutionalized worldwide framework for exchange and accreditation. To help the advancement and execution of such worldwide affirmation measures, Vattenfall is an individual from the Economical Biomass Association.

\section{CONCLUSION}

Biomass vitality is an essential option for giving vitality in our regular day to day existence. inexhaustible wellspring of vitality present day biomass can be a supportable wellspring of vitality, likewise reassuring the cogeneration plot. And further more learned about the creation of vitality in various parts in India. Biomass vitality use in industrialized nations is anticipated that would increment later on. With this potential vitality asset, world won't endure due to exhaustion of non-renewable energy sources if these possibilities are legitimately tapped and utilized 
and thus the production is done with the help of using different technologies like pyrolysis, combustion, decomposition, fermentation and gasification.

\section{REFERENCES}

1) Dr. Rajkumar, "Biomass power for rural energy and sustainable development in India Role of IREDA", Indian Renewable Energy Development Agency Ltd.

2) S. Rao, Dr. B.B. Parulekar, "Energy Technology, Nonconventional, Renewable and Conventional", 2nd Ed., New Delhi, Khanna Publishers, 1997.Paul Breeze, "Power Generation Technologies", Elsevier, 2005

3) M.V. Dael, S.V. Passel, L. Pelkmans, R. Guisson, P. Reumermann, N.M. Luzardo, N. Witters, J. Broeze, "A techno-economic evaluation of a biomass energy conversion park," Applied Energy, vol. 104, pp. 611-622, Apr. 2013.

4) M. Melikoglu, "Vision 2023: Feasibility analysis of Turkey's renewable energy projection," Renew. Energy, vol. 50, pp. 570-575, Feb. 2013.

5) H. Benli, "Potential of renewable energy in electrical energy production and sustainable energy development of Turkey: Performance and policies," Renew. Energy, vol. 50, pp. 33-46, Feb. 2013.

6) A. Daigneault, B. Sohngen, and R. Sedjo, "Economic approach to assess the forest carbon implications of biomass energy," Environmental Science \& Technology, vol. 46, pp. 5664-5671, 2012.

7) G.-B. Hong, T.-L. Su, J.-D. Lee, T.-C. Hsu, and H.-W. Chen, "Energy conservation potential in Taiwanese textile industry," Energy Policy, vol. 38, pp. 7048-7053, Nov. 2010.
8) H.S. Karaalp and N.D. Yilmaz, "Assessment of trends in the comparative advantage and competitiveness of the Turkish textile and clothing industry in the enlarged EU market," Fibres \& Textiles in Eastern Europe, vol. 3, pp. 8-12, 2012.

9) J.A. Fuinhas and A.C. Marques, "Energy consumption and economic growth nexus in Portugal, Italy, Greece, Spain and Turkey: An ARDL bounds test approach (1965-2009)," Energy Economics, vol. 34, pp. 511-517, Mar. 2012.

10) C.A. Basha, J. Sendhil, K.V. Selvakumar, P.K.A. Muniswaran, C.W.Lee, "Electrochemical degradation of textile dyeing industry effluent in batch and flow reactor systems," Desalination, vol. 285, pp. 188-197, Jan. 2012.

11) H. Zhao, Q. Wu, Sh. Hu, H. Xu, and C.N. Rasmussen, "Review of energy storage system for wind power integration support," Journal of Applied Energy, Volume 137, Issue 1, pp. 545553, 2015.

12) D. Easan, P. Denholm, and R. Sioshansi, "The value of compressed air energy storage in energy and reserve markets," Journal of Energy, Volume 36, Issue 8, pp. 4959-4973, 2011.

13) H. Pourbabak, T. Chen, W. Su, "Consensus-based Distributed Control for Economic Operation of Distribution Grid with Multiple Consumers and Prosumers," IEEE PES General Meeting Conference, Boston, MA, July 17-22, 2016.

14) A. Kumar, G. Bam, B. Sah, and P. Kumar, "A hybrid microgrid for remote village in himalayas," 3rd Renewable Power Generation Conference, Naples, Italy, Sep. 24-25, 2014, pp. 1 - 6. 